\title{
Functional study of a genetic marker allele associated with resistance to Ascaris suum in pigs
}

Skallerup, Per; Thamsborg, Stig M.; Jørgensen, Claus B.; Enemark, Heidi L.; Yoshida, Ayako; Göring, Harald H. H.; Fredholm, Merete; Nejsum, Peter

\author{
Published in: \\ Parasitology
}

Link to article, DOI:

$10.1017 /$ S0031182013002175

Publication date:

2014

Document Version

Publisher's PDF, also known as Version of record

Link back to DTU Orbit

Citation $(A P A)$ :

Skallerup, P., Thamsborg, S. M., Jørgensen, C. B., Enemark, H. L., Yoshida, A., Göring, H. H. H., Fredholm, M., \& Nejsum, P. (2014). Functional study of a genetic marker allele associated with resistance to Ascaris suum in pigs. Parasitology, 161(6), 777-787. https://doi.org/10.1017/S0031182013002175

\section{General rights}

Copyright and moral rights for the publications made accessible in the public portal are retained by the authors and/or other copyright owners and it is a condition of accessing publications that users recognise and abide by the legal requirements associated with these rights.

- Users may download and print one copy of any publication from the public portal for the purpose of private study or research.

- You may not further distribute the material or use it for any profit-making activity or commercial gain

- You may freely distribute the URL identifying the publication in the public portal 


\title{
Functional study of a genetic marker allele associated with resistance to Ascaris suum in pigs
}

\author{
PER SKALLERUP ${ }^{1,2}$, STIG M. THAMSBORG ${ }^{1}$, CLAUS B. JØRGENSEN ${ }^{2}$, \\ HEIDI L. ENEMARK ${ }^{3}$, AYAKO YOSHIDA ${ }^{4}$, HARALD H. H. GÖRING ${ }^{5}$, \\ MERETE FREDHOLM ${ }^{2}$ and PETER NEJSUM ${ }^{1,2}$ \\ ${ }^{1}$ Parasitology and Aquatic Diseases, Department of Veterinary Disease Biology, University of Copenhagen, Dyrlogevej 100, \\ DK-1870 Frederiksberg C, Denmark \\ ${ }^{2}$ Genetics and Bioinformatics, Department of Veterinary Clinical and Animal Sciences, University of Copenhagen, \\ Grønnegårdsvej 3, DK-1870 Frederiksberg C, Denmark \\ ${ }^{3}$ Section for Bacteriology, Pathology and Parasitology, National Veterinary Institute, Bülowsvej 27, \\ DK-1870 Frederiksberg C, Denmark \\ ${ }_{5}^{4}$ Department of Infectious Diseases, Division of Parasitology, Faculty of Medicine, University of Miyazaki, Japan \\ ${ }^{5}$ Texas Biomedical Research Institute, 7620 N. W. Loop 410, San Antonio, TX, USA
}

(Received 28 May 2013; revised 9 August and 26 September 2013; accepted 1 November 2013; first published online 5 February 2014)

\section{SUMMARY}

Two single nucleotide polymorphisms (SNP TXNIP and SNP ARNT), both on chromosome 4, have been reported to be associated with roundworm (Ascaris suum) burden in pigs. In the present study, we selected pigs with two SNP TXNIP genotypes (AA; $n=24$ and AB; $n=24$ ), trickle-infected them with $A$. suum from 8 weeks of age until necropsy 8 weeks later, and tested the hypothesis that pigs with the AA genotype would have higher levels of resistance than pigs of AB genotype. We used different indicators of resistance (worm burden, fecal egg counts (FEC), number of liver white spots and $A$. suumspecific serum IgG antibody levels). Pigs of the AA genotype had lower mean macroscopic worm burden (2.4 vs 19.3; $P=0.06)$, lower mean total worm burden $(26.5$ vs $70 \cdot 1 ; P=0.09)$ and excreted fewer $A$. suum eggs at week 8 PI (mean number of eggs/g feces: 238 vs 1259; $P=0 \cdot 14$ ) than pigs of the AB genotype, as expected based on prior associations. The pigs were also genotyped at another locus (SNP ARNT) which showed a similar trend. This study provides suggestive evidence that resistant pigs may be selected using a genetic marker, TXNIP, and provides further support to the quantitative trait locus on chromosome 4.

Key words: Ascaris suum, pig, single nucleotide polymorphism, resistance, immunity, host genetics, TXNIP, ARNT, genetic marker.

\section{INTRODUCTION}

Helminth infections in livestock remain a global challenge despite decades of research efforts. In pigs, infections with the nematode Ascaris suum occur worldwide in both intensive and extensive production systems (e.g. Peng et al. 1996; Nissen et al. 2011) and a recent survey showed that $A$. suum was found on $76 \%$ of Danish sow farms (Haugegaard, 2010). Ascaris suum infections may cause decreased weight gain and also give rise to liver condemnation at slaughter due to white spots caused by migrating larvae (reviewed by Thamsborg et al. 2013). With the risk of emergence of anthelmintic resistance, alternatives to chemotherapy are highly warranted to ensure sustainable control in the future (reviewed by Hoste and Torres-Acosta, 2011).

Since the early decades of the last century there has been a growing awareness that livestock breeds

* Corresponding author. Parasitology and Aquatic Diseases, Department of Veterinary Disease Biology, University of Copenhagen, Dyrlægevej 100, DK-1870 Frederiksberg C, Denmark. E-mail: pesk@sund.ku.dk differ in resistance to gastrointestinal nematodes due to genetic variation (Ackert et al. 1935; Johnson et al. 1975; Mugambi et al. 1997; Gauly et al. 2002; Oliveira et al. 2009; reviewed by Saddiqi et al. 2011). Work in laboratory models has shown similar differences in resistance between host strains (Dow and Jarrett, 1960; Mitchell et al. 1976; Lewis et al. 2006). We here define resistance as the ability to suppress establishment and/or subsequent development of infection due to development of immunity (Albers et al. 1987; Coustau et al. 2000) and we define susceptibility as the inverse of resistance (Gray, 1995). Helminths typically induce a polarized $\mathrm{T}_{\mathrm{H}} 2$-type response which includes both innate and adaptive components (Dawson et al. 2005; reviewed by Anthony et al. 2007 and Pulendran and Artis, 2012).

At the population level helminths are usually highly over-dispersed with a fraction of the individuals harbouring the majority of the parasites (e.g. Crofton, 1971; Croll et al. 1982) and there is now increasing evidence that this distribution to a large extent can be explained by genetic variation among hosts (reviewed by Quinnell, 2003). 
Indeed, quantitative genetic studies of different nematode infection traits (worm burden, fecal egg counts (FEC), worm length) have found medium to high heritabilities in both human and domestic animal populations, including pigs (reviewed by Kloosterman et al. 1992; Stear et al. 1997; Williams-Blangero et al. 1999; Zinsstag et al. 2000; Nejsum et al. 2009a). QTL (quantitative trait locus) studies have found several regions of the genome that apparently are involved in resistance to helminths (Iraqi et al. 2003; Dominik et al. 2010; Silva et al. 2012). However, in many cases, these QTLs have not been validated in independent populations and the underlying genes explaining the differences in susceptibility have not yet been identified.

In pigs, a QTL on chromosome 4 associated with resistance to $A$. suum was recently detected (Skallerup et al. 2012). The authors found two single nucleotide polymorphisms (SNPs), 0_TXNIP_ DS087128.1_2_2 (TXNIP) and 0_ARNT DS076761.1_18 (ARNT), which were associated with total worm burden and/or adult worm burden in cross-bred Danish Duroc/Landrace/Yorkshire (DLY) pigs. Hence, pigs with the 'resistant' AA genotype at the TXNIP locus had a mean total burden of 16 worms, whereas pigs with the 'susceptible' AB genotype had a mean burden of 41 worms, i.e. the heterozygotes had a $2 \cdot 5$-fold higher total worm burden than the homozygotes (Skallerup et al. 2012). The present study was conducted in an independent group of cross-bred DLY pigs from a commercial farm which were selected based on their SNP TXNIP genotype (AA, AB). These pigs were then experimentally infected with $A$. suum to validate the hypothesis that pigs with the AA genotype would have lower worm burdens than pigs with the $\mathrm{AB}$ genotype.

\section{MATERIALS AND METHODS}

\section{Experimental animals}

Previous research has shown that individuals homozygous for the $\mathrm{B}$ allele at the SNP 0_TXNIP DS087128.1_2_2 (TXNIP) locus have a low frequency in Danish mixed breed pigs and that this allele seems to be associated with $A$. suum susceptibility (Skallerup et al. 2012). Hence, it was only possible to include two genotypes (AA, $\mathrm{AB}$ ) in the study. Power analysis showed that a group size of 24 pigs would be sufficient to demonstrate a significant difference in macroscopic $A$. suum burden between the two SNP TXNIP genotypes, assuming an effect size similar to our previous study $(\sim 2 \cdot 5$-fold higher mean worm burden in heterozygous pigs compared with pigs homozygous for the allele increasing resistance). In order to identify pigs with the genotypes needed for the study, 112 cross-bred piglets (Danish Landrace/Yorkshire/Duroc) on a commercial specific pathogen-free farm were screened prior to inclusion. Mucosa cells from the oral cavity for DNA extraction were obtained using a gynobrush (Abena Ltd., Aabenraa, Denmark) and piglets were genotyped as described below. All genotypes were validated using DNA from blood samples taken on day 55 post first infection (PI).

\section{Housing}

The study was approved by the Animal Experiments Inspectorate, Ministry of Justice, Denmark (Ref. 2010/561-1914). Care and maintenance of all animals were in accordance with applicable Danish and European guidelines. Fifty-two pigs $\left(N_{\mathrm{AA}}=27\right.$; $N_{\mathrm{AB}}=25$ ) from 10 different litters (two to eight piglets from each litter) were selected for the study. The farmer used mixed semen to produce the littermates which were thus full-sibs or half-sibs. The pigs were kept at the animal facility at the National Veterinary Institute, Denmark; upon arrival at 7 weeks of age they were allocated into three pens with concrete floors ensuring an equal distribution of genotype, litter of origin, sex and weight in each pen. The pens were littered with wood shavings on a daily basis, and water was provided ad libitum. In order to optimize worm establishment, the animals were fed a diet consisting of ground barley supplemented with proteins and minerals (Petkevicius et al. 1995; Bjorn et al. 1996). The piglets were treated prophylactically against Lawsonia spp. (tiamulin (Denagard $\mathrm{Vet}^{\mathbb{B}}$ ) $10-25 \mathrm{mg} \mathrm{kg}^{-1}$ intramuscularly for 3 days) during the first week. Mean weight ( \pm S.D.) of the AA and AB groups on day 0 PI was $13.5 \mathrm{~kg}( \pm 2.5)$ and $13.4 \mathrm{~kg}$ $( \pm 2 \cdot 4)$, respectively.

\section{Phenotypic traits}

The experimental protocol to generate parasite indicator traits involved trickle infections with A. suum. Hence, after 1 week of acclimatization, pigs of $\mathrm{AA}$ and $\mathrm{AB}$ genotypes $\left(N_{\mathrm{AA}}=27 ; N_{\mathrm{AB}}=25\right)$ were experimentally infected with $A$. suum eggs $\left(25 \mathrm{eggs} \mathrm{kg}^{-1} \mathrm{day}^{-1}\right)$ twice per week. One pig of each genotype was euthanized on day $13 \mathrm{PI}$ as described below; in addition, two pigs of genotype AA died during the experiment and were excluded from the analysis. Based on previous experience (Nejsum et al. 2009a, b), the utilized inoculation dose was expected to give a high prevalence of macroscopic worms. Embryonated parasite eggs used for infections were prepared from female $A$. suum worms collected at a Danish slaughterhouse as described elsewhere (Oksanen et al. 1990). The first egg suspension was given orally via a plastic syringe at the base of the tongue; subsequently, the eggs were given in the feed on a pen basis.

The pigs were euthanized using a captive bolt pistol followed by exsanguination on days 55-59 PI. 
After removing the viscera, the small intestine was opened longitudinally, washed in lukewarm saline $(0.9 \%)$ and gently pulled between two fingers to remove the mucus. Any macroscopic $A$. suum worms (large juveniles and adults) were removed and counted. Ascarid larvae were isolated by the agargel method (Slotved et al. 1997) and total larval burden calculated by extrapolation from a $20 \%$ aliquot count. All worms were stored in $70 \%$ ethanol until they were counted. The liver was carefully examined, and white spots caused by migrating larvae were counted and classified as the diffuse granulation-tissue type or the lymphonodular type (Ronéus, 1966; Copeman and Gaafar, 1972); all livers were examined by the same person who was blinded to pig genotype. The infectivity of the $A$. suum egg batch was tested in two pigs (one AA and one AB) which were euthanized on day $13 \mathrm{PI}$, and the number of larvae in the small intestine assessed as described above (larval burden was calculated by extrapolation from a $50 \%$ aliquot count). The recovery was $32 \%$ (AA pig) and $42 \%$ (AB pig) of the total dose given on days 0 and 3 PI.

Feces were sampled rectally at day 0 PI and weekly from week 5 PI until slaughter. Egg counts were determined using a modified McMaster method with an analytical sensitivity of 20 eggs per gram of feces (epg) (Roepstorff and Nansen, 1998). Samples taken at week 8 PI were processed and counted in duplicate, and the mean of the two measurements was used in the statistical analysis.

Blood samples were collected on days -3 (two pens), 0 (one pen) and 55 PI (all pens) to test the antibody response to $A$. suum antigen preparations. Blood samples were refrigerated overnight and subsequently centrifuged $(1763 \boldsymbol{g}, 10 \mathrm{~min})$. Serum was then frozen at $-20{ }^{\circ} \mathrm{C}$ until analysis. Whole-blood samples (EDTA tubes) were taken on day $55 \mathrm{PI}$ and kept at $-20^{\circ} \mathrm{C}$ until analysis.

For the preparation of adult $A$. suum (adult-As) antigen, adult worms were collected at a slaughterhouse in Japan, homogenized and incubated at $5{ }^{\circ} \mathrm{C}$ overnight. The extract was centrifuged $(14000 \mathrm{~g}$, $10 \mathrm{~min}, 5^{\circ} \mathrm{C}$ ) and the supernatant was then isolated.

Ascaris suum lung L3 larvae (LL3) were collected from male Japanese white rabbits (Kyodo, Kumamoto, Japan) using the Baermann method as described elsewhere (Yoshida et al. 2012). LL3 larvae were cultured $\left(37^{\circ} \mathrm{C}\right)$ in 6 -well culture plates (Nunc, Roskilde, Denmark) containing RPMI 1640 medium (Wako, Osaka, Japan) supplemented with $100 \mu \mathrm{g} \mathrm{mL}^{-1}$ of streptomycin, $100 \mathrm{U} \mathrm{mL}^{-1}$ of penicillin and $250 \mathrm{ng} \mathrm{mL}^{-1}$ of amphotericin B (all from Gibco, Rockville, MD, USA). Supernatants were collected 7, 14, 21 and 28 days after incubation, pooled, and subsequently concentrated using ultrafiltration (Amicon ${ }^{\circledR}$ Ultra-15 3K, Millipore, Billerica, MA, USA). LL3 excretory/secretory antigen (LL3-ES) concentration was determined by
Quant-iTTM Protein Assay Kit (Invitrogen, Carlsbad, CA, USA).

Infective $A$. suum L3 larvae (iL3) were produced from eggs isolated from female worms collected at a slaughterhouse in Japan. The eggs were kept in sulphuric acid $(0 \cdot 1 \mathrm{~N})$ and embryonated ( 8 weeks, $27^{\circ} \mathrm{C}$ ), then mechanically hatched in a beaker with $1 \cdot 5-2.5 \mathrm{~mm}$ glass beads $\left(30 \mathrm{~min}, 37^{\circ} \mathrm{C}\right)$. The suspension was passed through a $425 \mu \mathrm{m}$ sieve to remove glass beads, then larvae were isolated by the Baermann method and cultured as described above. iL3 excretory/secretory antigen (iL3-ES) was obtained from pooled culture supernatants collected 7 , 14, 21 and 28 days after incubation, then concentrated and its protein concentration assessed as described for LL3-ES.

Flat-bottomed 96-well plates (MaxiSorp, Nunc, Roskilde, Denmark) were coated with adult-As, LL3-ES or iL3-ES $A$. suum antigen $\left(1 \mu \mathrm{g} \mathrm{mL}^{-1}\right.$; $\left.50 \mu \mathrm{L} \mathrm{well}^{-1}\right)$ in $0.05 \mathrm{M}$ carbonate-bicarbonate coating buffer ( $\mathrm{pH} 9 \cdot 6)$ and incubated at $5{ }^{\circ} \mathrm{C}$ overnight. The plates were washed three times with PBST (0.01 M phosphate, 0.15 M sodium chloride, pH 7.2 and $0.05 \%$ Tween 20$)$ in a microplate washer (BioTek, Winooski, VT, USA), blocked with $150 \mu \mathrm{L}$ $10 \%$ caseine TBS per well and incubated for $2 \mathrm{~h}$ at room temperature (RT). Serum diluted 1:1000 (adult-As), 1:2000 (LL3-ES), or 1:500 (iL3-ES) in $10 \%$ caseine TBS was added to each well ( $50 \mu \mathrm{L}$ well $\left.{ }^{-1}\right)$, incubated for $1.5 \mathrm{~h}$ at RT, and wells were then washed again three times. Fifty $\mu \mathrm{L}$ horseradish peroxidase-labelled goat anti-swine IgG (gamma chain) (KPL, Gaithersburg, MD, USA) diluted 1:2000 in 10\% caseine TBS buffer was added to each well and incubated for $1.5 \mathrm{~h}$ at RT. The plates were washed three times and incubated $10 \mathrm{~min}$ at RT

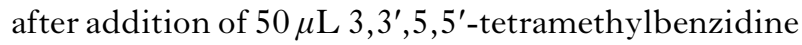
(KPL, Gaithersburg, MD, USA) to each well. The reaction was stopped with $25 \mu \mathrm{L}$ sulphuric acid (1 M) per well and OD values were read at $450 \mathrm{~nm}$ (Multiskan EX, MTX Lab Systems Inc, VA, USA). As positive control we used a single anti- $A$. suum IgG positive serum sample from a pig trickle-infected with A. suum.

\section{DNA extraction and SNP genotyping}

DNA was extracted from oral mucosa cells using the Wizard $^{\circledR}$ Genomic DNA Purification kit (Promega, Madison, WI, USA) according to the manufacturer's instructions. The quantity and quality of DNA was measured using a NanoDrop 1000 spectrophotometer (Thermo Fischer Scientific). Genotyping was performed using a custom-made TaqMan $^{\circledR}$ SNP Genotyping Assay (Applied Biosystems, Carlsbad, CA, USA) on a Stratagene Mx3000PTM (Agilents, Santa Clara, CA, USA). All assays were run in a total volume of $15 \mu \mathrm{L}$ with $20 \mathrm{ng}$ of genomic DNA as 
template according to the manufacturer's instructions. The PCR programme was as follows: Initial denaturation $\left(95^{\circ} \mathrm{C}, 10 \mathrm{~min}\right)$ followed by 48 cycles $\left(92^{\circ} \mathrm{C}, 20 \mathrm{~s} ; 60^{\circ} \mathrm{C}, 1 \mathrm{~min}\right)$. The MxPro software (Stratagene) was used for allele discrimination. All animals included in the final analysis $(N=48)$ had their genotypes validated using DNA from wholeblood samples. DNA was extracted using a salting out procedure as described by Miller et al. (1988) with minor modifications. The quantity and quality of DNA was measured as described above.

Location of single nucleotide polymorphisms and quantitative trait locus associated with $\mathrm{A}$. suum burden

In the recent assembly (sscrofa10.2) of the porcine genome (Groenen et al. 2012) (http://www.ensembl.org), the QTL associated with resistance to $A$. suum (Skallerup et al. 2012) maps to SSC4: 106,139,259$109,133,240$. This region is flanked by the genes TCHHL1 and POLR3C. In sscrofa10.2, SNP TXNIP maps to SSC4: 108,992,540; SNP ARNT maps to SSC4: $107,609,772$.

\section{Statistical analyses}

Power analysis ( $80 \%$ power; $5 \%$ significance level) was performed in $\mathrm{R}$ ( $\mathrm{R}$ Core Team, 2012) using power.t.test. Effect size $(0.73)$ and variance estimates were calculated from log-transformed macroscopic worm burden data from a previous trickle-infection study using the same dose and which showed that the 'susceptible' genotype had 2.5-fold higher mean worm burden than the 'resistant' genotype (Nejsum et al. 2009a; Skallerup et al. 2012).

The association analyses between the two single nucleotide polymorphisms (SNPs) and traits related to $A$. suum infection were performed using a measured genotype approach (Boerwinkle et al. 1986) as implemented in the software package SOLAR version 4.2.7 (Texas Biomedical Research Institute, San Antonio, TX, USA) (Almasy and Blangero, 1998). Sex and starting weight were fitted as fixed effects and litter and pen were fitted as random effects (to account for additive genetic effects and shared environmental effects, respectively). SNP genotypes were converted into measured covariates (fixed effects) by coding the number of copies of the rarer allele (0-2) thus assuming additivity of allelic effects. The measured genotype analysis tests whether there is a significant difference between the genotypic means (Havill et al. 2005).

In the analyses, each pen was treated as a separate household with shared environment. Since the farmer used mixed semen, we had no information about paternal origin of the piglets. Hence, we conservatively modelled that all piglets in each litter had the same father (i.e. assuming that piglets were full sibs

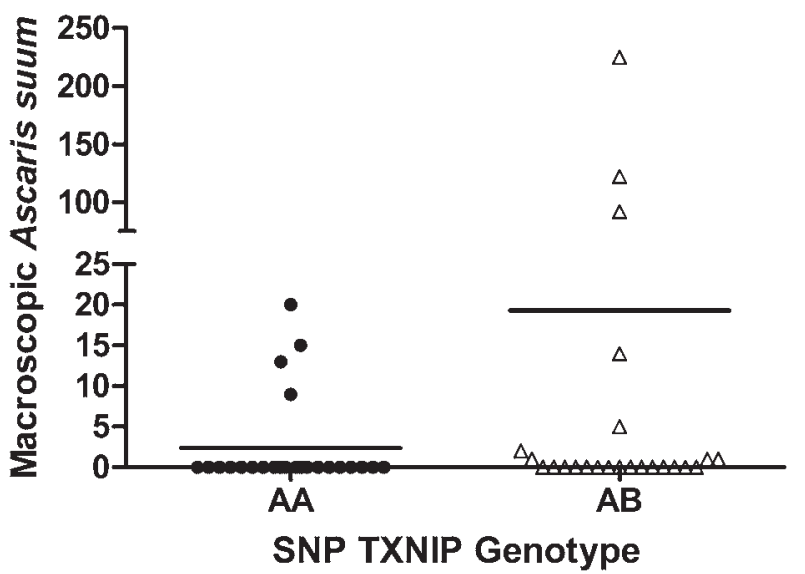

Fig. 1. Number of macroscopic Ascaris suum in individual pigs homozygous $(N=24)$ or heterozygous $(N=24)$ at the single nucleotide polymorphism (SNP) 0_TXNIP_DS087128.1_2_2 (TXNIP) locus. Means are indicated with horizontal lines.

and thus more related to each other than they probably were in reality), and that different litters were unrelated (i.e. we modelled that each sow was sired to one of nine designated model boars).

Data were normalized prior to analysis, if needed, using either the $\log 10$ transformation (total A. suum burden, FEC, lymphonodular type liver white spots) or the inverse Gaussian density distribution (macroscopic A. suum) to ensure that the phenotypes did not violate the assumptions underlying variance components analysis. Based on previous work (Skallerup et al. 2012) we expected a priori pigs in the AB group to have higher worm burdens than pigs in the AA group. Hence, in the analyses of macroscopic worm burden, total worm burden and FEC, we used a one-sided test whereas for the other traits we used a two-sided test. We chose a significance level of $P=0 \cdot 05$. The correlation between worm burdens and $A$. suum-specific antibody titres was determined from the Spearman correlation coefficient calculated in GraphPad Prism version 5.04 for Windows (GraphPad Software, San Diego, CA, USA).

\section{RESULTS}

Piglets were confirmed negative for $A$. suum infection as tested by FEC day 0 PI. In addition, all pigs were found seronegative to adult-As antigen before the start of the experiment. Two pigs of genotype AA died during the experiment for reasons not related to the study treatment and were excluded from the analysis.

A total of 13 pigs (4 of AA genotype and 9 of AB genotype) had macroscopic $A$. suum at slaughter (Fig. 1; Table 1). Three pigs (all in the AB group) had more than 90 macroscopic $A$. suum. Mean $A$. suum intensity of $\mathrm{AB}$ pigs was 3.6 times higher than in $\mathrm{AA}$ 


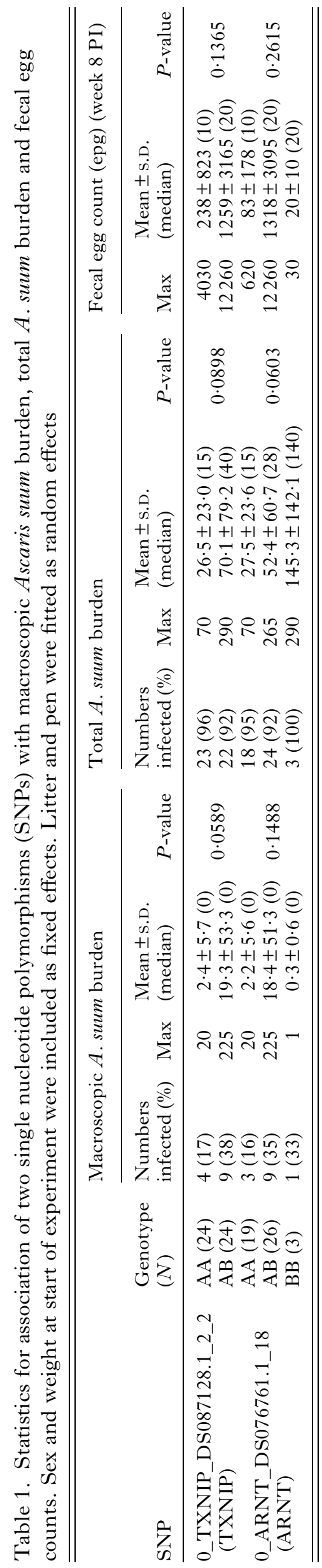

pigs and the difference in abundance between the two genotypes approached significance $(P=0 \cdot 06)$.

Previous work in our group has confirmed the association of another SNP, ARNT, with adult $A$. suum burden (Skallerup et al. 2012), and pigs were thus genotyped at the ARNT locus as well. The linkage disequilibrium $\left(r^{2}\right)$ between the two SNPs (TXNIP, ARNT) was estimated to be $0 \cdot 78$. All three genotypes of the ARNT polymorphism were found and genotypic means for the different traits are presented in Tables 1 and 2. The AB genotype (SNP ARNT) had higher mean macroscopic $A$. suum burden than the AA genotype (18.4 vs 2.2; Table 1; $P=0 \cdot 15)$, with the direction of effect being as expected. Only one of the three pigs with genotype BB harboured macroscopic worms (one worm; Table 1).

For total worm burden we found the same trend as for the macroscopic worms; pigs with the AB genotype (SNP TXNIP) had $\sim 2 \cdot 6$ times higher total worm burden (both measured as mean and median) than the AA genotype (Table 1, Fig. 2; $P=0 \cdot 09$ ). A similar tendency was seen for SNP ARNT; one copy of the susceptibility allele (B) doubled the total worm burden (both measured as mean and median) whereas carriers of two copies (BB) had a mean worm burden nearly three times higher than the heterozygotes (Fig. 3; Table 1; $P=0 \cdot 06$ ).

Ascaris suum eggs were detected from week $6 \mathrm{PI}$ and onwards (Fig. 4). At week 8 PI, AB pigs (SNP TXNIP) excreted $\sim 5$ times more eggs than AA pigs but the difference was not significant (Table 1). A similar picture was seen for SNP ARNT.

All pigs had liver white spots at necropsy (Table 2). There was hardly any difference in total number of liver white spots between the $\mathrm{AA}$ and $\mathrm{AB}$ genotypes for both SNPs, although pigs of the BB genotype (SNP ARNT) tended to have higher numbers (Table 2). When considering only the pearl-like white spots (lymphonodular spots), the heterozygotes (SNP TXNIP) had a slightly higher mean number than homozygotes $(10.6$ vs $7 \cdot 6$; Table 2 ; $P=0 \cdot 33)$. A similar effect was seen for the AA and AB genotypes at SNP ARNT while carriers of two copies of the susceptibility allele had twice as many lymphonodular spots as the heterozygotes $(P<0 \cdot 05)$.

OD values for serum $\operatorname{IgG}$ antibody response to the different antigens are presented in Table 2. For all three antigens tested (adult-As Ag, iL3-ES Ag and LL3-ES Ag), the AB group (TXNIP, ARNT) had higher antibody titres than the AA group. The effect of SNP TXNIP was strongest for the adult A. suumspecific antibody response but did not reach significance $(P=0 \cdot 11)$. By merging the two genotypes, we found a significant positive correlation between total worm burden and adult $A$. suum-specific IgG antibody titre $(P<0 \cdot 05)$, and between total worm burden and LL3-ES specific IgG antibody titre $(P<0 \cdot 05)$. Macroscopic worm burden was not correlated with 


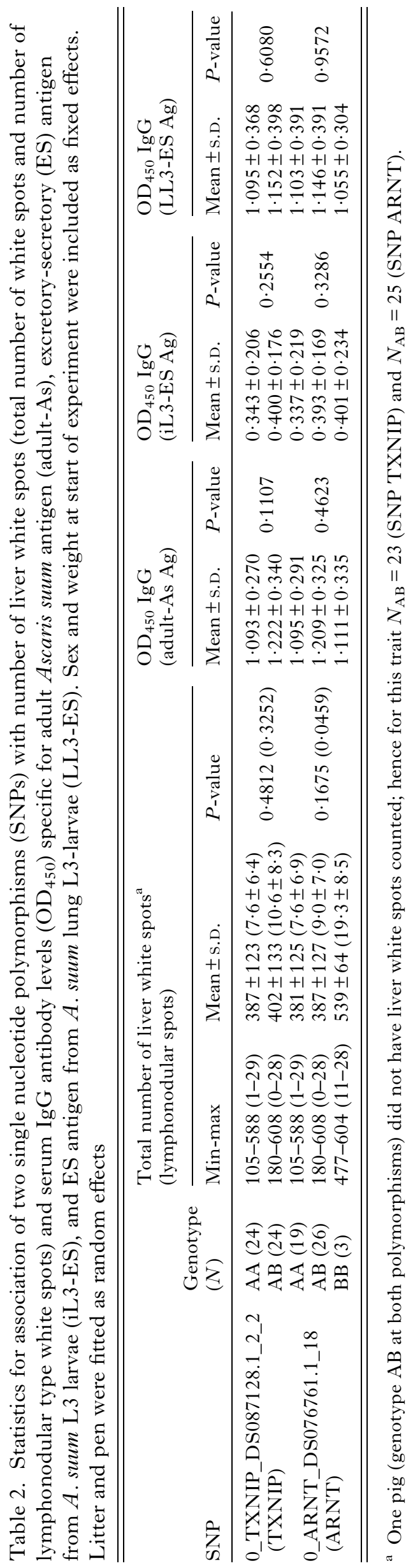

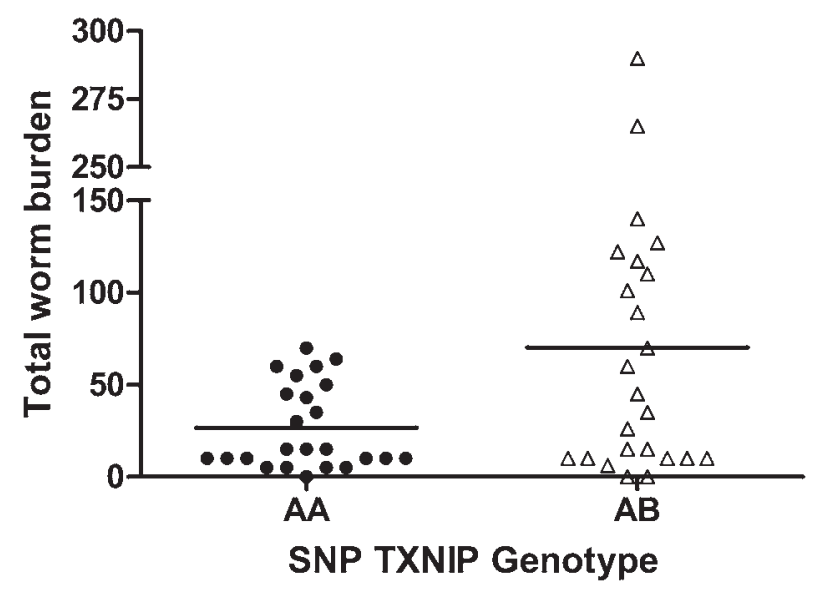

Fig. 2. Total number of Ascaris suum in individual pigs homozygous $(N=24)$ or heterozygous $(N=24)$ at the single nucleotide polymorphism (SNP) 0_TXNIP_ DS087128.1_2_2 (TXNIP) locus. Means are indicated with horizontal lines.

serum antibody response to any of the three antigens tested (data not shown).

\section{DISCUSSION}

Previous work by our group has demonstrated that A. suum burden is under genetic regulation (Nejsum et al. 2009a); in addition, we have detected a QTL encompassing one or more of these genes on the porcine chromosome 4 (Skallerup et al. 2012). The present study was designed to provide proof-ofprinciple that pigs resistant to $A$. suum infection can be identified based on their specific SNP genotype at a specific locus (SNP TXNIP) on chromosome 4. We selected piglets of two SNP TXNIP genotypes (AA, AB) from 10 different litters which were then A. suum trickle-infected for 8 weeks after which we compared the two groups. We used different indicators of resistance (worm burden, FEC, number of liver white spots and $A$. suum-specific serum $\operatorname{IgG}$ antibody levels) of which the first two traits were considered core traits and the last two traits were associated traits. Although the differences between the two genotypes were not significant, we found a consistent trend particularly across the core phenotypic traits examined; hence, the 'resistant' AA (TXNIP) genotype had fewer $A$. suum (both measured as macroscopic worm burden and total worm burden) and excreted fewer eggs throughout the study than the 'susceptible' AB genotype (Table 1). Hence, our data suggest that resistant pigs can be selected using the TXNIP marker and that the B allele is associated with susceptibility to $A$. suum infection.

The burden of macroscopic $A$. suum is a useful and convenient measure of resistance. In pigs that are continually exposed to $A$. suum, most larvae are prevented from reaching the liver (Urban et al. 1988; 


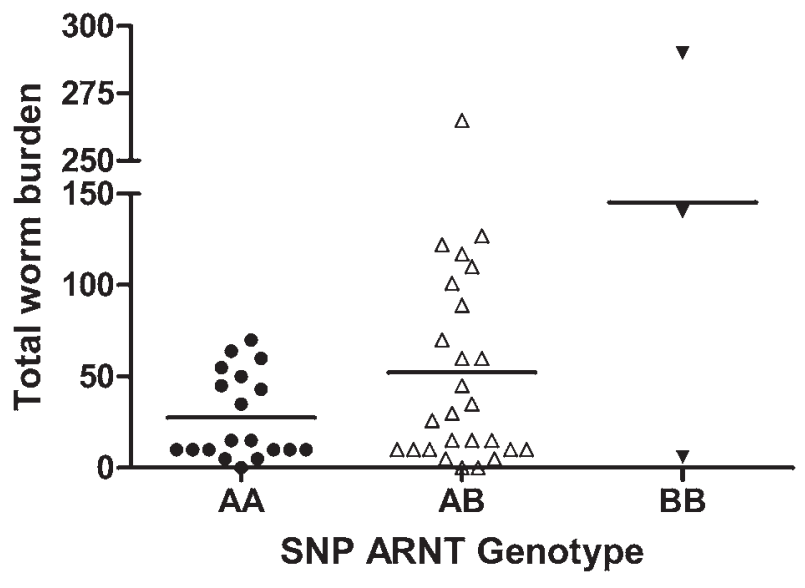

Fig. 3. Total number of Ascaris suum in individual pigs homozygous $\left(N_{\mathrm{AA}}=19 ; N_{\mathrm{BB}}=3\right)$ or heterozygous $\left(N_{\mathrm{AB}}=26\right)$ at the single nucleotide polymorphism (SNP) 0_ARNT_DS076761.1_18 (ARNT) locus. Means are indicated with horizontal lines.

Stankiewicz and Jeska, 1990; Jungersen et al. 1999) and large, patent worms seem to originate from the early phase of exposure (Mejer and Roepstorff, 2006; Nejsum et al. 2009b). In this early phase, the prehepatic barrier is not very effective and although some larvae are trapped in the liver parenchyma (Ronéus, 1966; Pérez et al. 2001) and possibly the lung, nearly $50 \%$ may be recovered in the small intestine shortly after infection (Roepstorff et al. 1997; Helwigh and Nansen, 1999). The majority will normally be expelled between day 14 and 30 PI, depending on the infection regime, and this immune reaction (Miquel et al. 2005) leaves a small fraction of larvae which grow to maturity (Schwartz, 1959; Jorgensen et al. 1975; Roepstorff et al. 1997; Nejsum et al. 2009b).

Unfortunately, the surprisingly low prevalence of macroscopic worms in our study made it difficult to determine to what extent the SNP TXNIP marker was associated with this trait; only $38 \%$ of $\mathrm{AB}$ (TXNIP) pigs were positive for this phenotype $v s$ $17 \%$ of AA pigs which, however, is twice as high in 'susceptible' pigs compared with 'resistant' pigs. The prevalences of macroscopic $A$. suum in the present study were lower than in previous experimental trickle infections using the same infection protocol (Nejsum et al. 2009a,b). In two of the pens we found a lower prevalence (24 and 13\%) than in the third (44\%) even though the conditions were kept similar, i.e. same $A$. suum egg batch, feeding regime, stocking density and housing. Autoinfection is unlikely to have taken place because embryonation of $A$. suum eggs requires $10-14$ days at $30^{\circ} \mathrm{C}$ and more than 45 days at $17^{\circ} \mathrm{C}$ (reviewed by O'Lorcain and Holland, 2000). In our study, egg excretion started week 6 PI and the study was terminated 2 weeks later. Thus, there was no possibility for uncontrolled infection. The two pigs examined on day 13 PI (one from a 'high-prevalence' pen and one from a

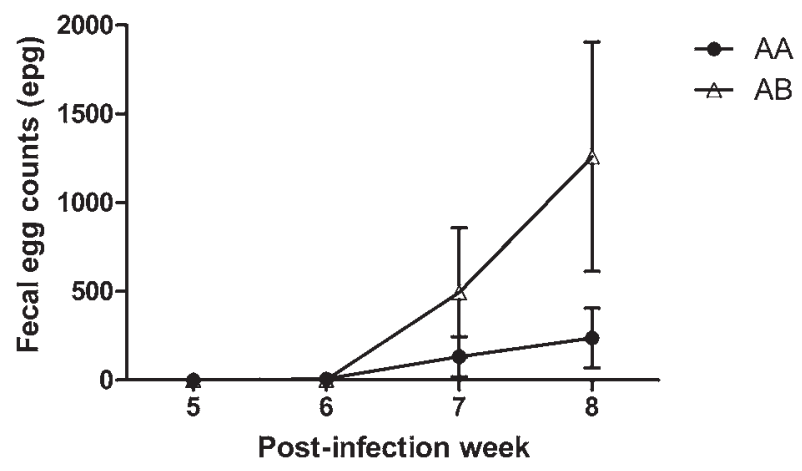

Fig. 4. Mean Ascaris suum fecal egg count (epg) during infection in pigs homozygous (circles; $N_{\mathrm{AA}}=24$ ) or heterozygous (triangles; $N_{\mathrm{AB}}=24$ ) at the single nucleotide polymorphism 0_TXNIP_DS087128.1_2_2 (TXNIP) locus. Error bars represent s.E. of the mean.

'low-prevalence' pen) showed recovery percentages similar to previous studies (Roepstorff et al. 1997). An analysis of a simulated dataset (assuming that pigs in all three pens had had same prevalence and intensities of macroscopic $A$. suum as the third pen) showed a significant association $(P=0.012)$ between macroscopic $A$. suum burden and SNP TXNIP.

As a second direct measure of the host's ability to suppress establishment and/or subsequent development of infection (Albers et al. 1987) we used total worm burden. While larvae recovered from the small intestine in the present study had completed migration, they were still vulnerable to expulsion, i.e. some of these larvae would probably have been expelled from the small intestine if the pig had been necropsied at a later time-point (Mejer and Roepstorff, 2006; Nejsum et al. 2009b). We therefore expected the total worm burden trait to contain more noise (i.e. a smaller difference between 'susceptible' and 'resistant' pigs) than the macroscopic worm burden trait. Nevertheless, we found a clear trend with the AB group (TXNIP) having more than twice as many worms as the AA group (Table 1), most of which were larvae. These data suggest that part of the difference in worm burden among the two genotypes could be explained by differences in pre-hepatic barrier and/or losses during the hepato-tracheal migration. Comparing total worm burdens for the same SNP TXNIP genotypes, Skallerup et al. (2012) reported effects of a similar magnitude in their discovery and validation studies.

In addition to the two worm burden traits discussed above, we looked at FEC as another core trait. Pigs of the AA genotype (TXNIP) excreted fewer $A$. suum eggs throughout the experiment but the difference was not significant. Again, the lack of significance could be explained by the limited number of pigs with large, patent worms of which one pig did not even excrete eggs, possibly due to single-sex infection (Jungersen et al. 1997). Although several studies have shown a positive correlation between 
FEC and A. suum worm burden (Roepstorff and Murrell, 1997; Roepstorff et al. 1997; Boes et al. 1998), density-dependent reductions of fecundity may obscure the association between genetic markers and FEC (Croll et al. 1982; Anderson and Schad, 1985). In addition, egg counts have a large day-today variability e.g. due to variations in feed intake and consistency of feces and because of a nonhomogeneous distribution of eggs in the feces (Brown, 1927; Scott and Headlee, 1938; Croll et al. 1982; Anderson and Schad, 1985). Studies of trichostrongyles in sheep have demonstrated that genetic resistance mainly is due to control of worm length and fecundity rather than worm burden (Stear et al. 1997, 1999). In pigs, this does not seem to be the case since worm fecundity and worm size were not heritable in contrast to high heritability estimates for A. suum worm burden (Nejsum et al. 2009a; Skallerup et al. 2012). This might indicate that immunity against $A$. suum is directed towards the migrating and newly established larvae while different mechanisms could have evolved in non-migrating ruminant trichostrongyles.

Liver white spots develop as an immunepathological response to migrating ascarid larvae (Ronéus, 1966; Urban et al. 1988; Pérez et al. 2001). The number of liver white spots is related to number of larvae that have recently (within 3-6 weeks) migrated through the liver (Eriksen et al. 1980, 1992; Nejsum et al. 2009b) and in this study we used this parameter as an associated indicator trait for resistance. We expected that resistant pigs would have fewer liver white spots than susceptible pigs because they would more effectively establish a pre-hepatic barrier (Nejsum et al. 2009b). We did not find any differences in the number of liver white spots between the two variants of the TXNIP polymorphism and our results indicate that even in 'resistant' AA pigs, the pre-hepatic barrier was far from being complete at 8 weeks PI (Tables 1 and 2).

As a second associated trait, we looked at the A. suum-specific antibody production. For all antigens tested, the IgG antibody response was slightly higher in the $\mathrm{AB}$ group than in the AA group (SNP TXNIP), though not statistically significant. Previous work in experimentally and naturally infected pigs has shown a positive correlation between worm burden/FEC and IgG antibody titres (Roepstorff et al. 1997; Roepstorff, 1998; Vlaminck et al. 2012). Since AB pigs (SNP TXNIP) had higher worm burdens than AA pigs, our results are in agreement with these findings. Indeed, we found a significant positive correlation between total worm burden and adult $A$. suum-specific IgG antibody titres and between total worm burden and LL3-ES specific IgG antibody titres. Other studies in pigs, cattle and sheep have shown conflicting results (e.g. Gasbarre et al. 1993; Roepstorff and Murrell, 1997; Nejsum et al. 2009b; Zaros et al. 2010; Hassan et al. 2011).
The relationship between worm burden/FEC and antibody response is apparently complex and there are probably different genes regulating the two traits (Gasbarre et al. 1993).

In addition to the TXNIP locus, the pigs were also genotyped at another locus, SNP ARNT. In contrast to Skallerup et al. (2012) who only found two of the genotypes of SNP ARNT in their validation studies, we found all three genotypes of this SNP present in this study. In agreement with the high linkage disequilibrium between the two SNPs, we observed a similar phenotypic trend to SNP TXNIP for the $\mathrm{AA}$ and $\mathrm{AB}$ genotypes; hence, the AA genotype (SNP ARNT) had fewer A. suum (both measured as macroscopic worms and total worm burden), excreted fewer eggs at week 8 PI, and had lower serum IgG antibody levels at week $8 \mathrm{PI}$ than the $\mathrm{AB}$ genotype (Tables 1 and 2). Comparing pigs with genotype BB (SNP ARNT) with AA and AB pigs, there was no consistent trend and the low number of pigs $(N=3)$ carrying two copies of this susceptibility allele made it difficult to test the hypothesis that these pigs would have a 'hyper-susceptible' phenotype. Nevertheless, for two traits, i.e. mean total $A$. suum burden and mean number of lymphonodular spots, there was a clear effect of the BB genotype (Tables 1 and 2).

A number of linkage studies using microsatellites have dissected the genetics underlying parasite resistance (e.g. Iraqi et al. 2003; Davies et al. 2006; Coppieters et al. 2009) but SNP chip studies are becoming more common (Riggio et al. 2013). To date, the large majority of genome-wide association studies have identified SNP variants that explain only a small proportion of the genetic variance for complex traits (Dermitzakis and Clark, 2009; Manolio et al. 2009), including parasite resistance in domestic animals (Kemper et al. 2011; Sallé et al. 2012). Nevertheless, our SNP marker (TXNIP) seems to have a rather strong effect, with $\mathrm{AB}$ pigs having 2.5fold higher mean total worm burden than AA pigs both in the initial genome scan (Skallerup et al. 2012) and in the present functional study. A significant single-marker effect on worm burden has also been found in sheep. Hassan et al. (2011) produced twin lambs with different genotypes at the $M H C-D R B 1$ locus which were then experimentally infected with Teladorsagia circumcincta and subsequently necropsied at various time-points post infection. Despite small group sizes (four lambs per genotype per sampling day), the authors found that carriers of the $D R B 1 * 1101$ allele had significantly lower worm counts than non-carrier lambs. Non-carriers had approximately $0 \cdot 8-4$-fold higher mean worm burdens than carriers of the allele increasing resistance. While this significance could be explained by a stronger marker effect of $M H C-D R B 1$ than our TXNIP marker, it is also possible that the species difference in worm counts plays a role; hence, 
$T$. circumcincta occur in much higher numbers and with higher prevalences than $A$. suum.

Genetic markers can identify animals with desired traits for breeding programmes (Charlier et al. 2008; Nielsen et al. 2009; reviewed by Bishop, 2012). Care should be taken, though, to weigh the advantage against the loss of other beneficial alleles in linkage disequilibrium with the marker (Wolc et al. 2012), and ideally marker information from the whole genome (i.e. genomic selection) should be included (reviewed by Goddard and Hayes, 2007; Kemper et al. 2011). Our data provide suggestive evidence that $A$. suum resistant pigs can be identified using a genetic marker, TXNIP. We observed a consistent effect on two core traits (worm burden and FEC) and one associated trait (serum IgG antibody levels). Although we did not find a significant effect of genotype on worm burdens, the effects are in the exact same direction as expected and we believe it would be overly conservative to interpret data as if there were no effect of the marker. In the light of these considerations, we encourage further studies of the TXNIP marker. We believe the TXNIP marker which is located in intron 2 of the TXNIP gene is not the causative mutation ('disease locus') but most probably in linkage disequilibrium with one or more genes within the QTL on chromosome 4 that confer resistance to $A$. suum (Skallerup et al. 2012). The present study suggests that SNP ARNT is another diagnostic marker candidate for $A$. suum resistance and hence provides further support to the QTL detected previously (Skallerup et al. 2012) in agreement with the high linkage disequilibrium between these two SNPs. The total worm counts and liver white spot data presented in this paper indicate that protective immunity in the resistant group (TXNIP, ARNT) is expressed not only at the pre-hepatic barrier level (Urban et al. 1988; Masure et al. 2013) but at other sites as well. Further studies are required to elucidate the different immunological responses mounted by the two TXNIP genotypes and to investigate the effect of the four candidate genes within the QTL (TNFAIP8L2, PIAS3, RBM8A and $R F X 5)$ suggested by Skallerup et al. (2012).

\section{ACKNOWLEDGEMENTS}

The authors wish to thank all those who contributed to the research project which forms the basis of this paper: LiseLotte Christiansen, Christel Ammitzböll Halberg, Minna Jakobsen and Anne Strandsby provided excellent technical assistance. Hans Skaaning and his team took good care of the pigs and assisted with the data collection.

\section{F INANCIAL SUPPORT}

This work was supported by the Danish Agency for Science, Technology and Innovation (grant awarded to P. N.). P.S. is supported by a University of Copenhagen (Denmark) PhD grant.

\section{REFERENCES}

Ackert, J. E., Eisenbrandt, L. L., Wilmoth, J. H., Glading, B. and Pratt, I. (1935). Comparative resistance of five breeds of chickens to the nematode Ascaridia lineata (Schneider). Fournal of Agricultural Research 50, 607-624.

Albers, G. A., Gray, G. D., Piper, L. R., Barker, J. S., Le Jambre, L. F. and Barger, I. A. (1987). The genetics of resistance and resilience to Haemonchus contortus infection in young Merino sheep. International Fournal for Parasitology 17, 1355-1363.

Almasy, L. and Blangero, J. (1998). Multipoint quantitative-trait linkage analysis in general pedigrees. American fournal of Human Genetics 62, 1198-1211

Anderson, R. M. and Schad, G. A. (1985). Hookworm burdens and faecal egg counts: an analysis of the biological basis of variation. Transactions of the Royal Society of Tropical Medicine and Hygiene 79, 812-825.

Anthony, R. M., Rutitzky, L. I., Urban, J.F., Jr., Stadecker, M. J. and Gause, W. C. (2007). Protective immune mechanisms in helminth infection. Nature Reviews Immunology 7, 975-987.

Bishop, S. C. (2012). Possibilities to breed for resistance to nematode parasite infections in small ruminants in tropical production systems. Animal 6, 741-747.

Bjorn, H., Roepstorff, A. and Nansen, P. (1996). A possible influence of diet composition on the establishment of nematodes in the pig. Veterinary Parasitology 63, 167-171.

Boerwinkle, E., Chakraborty, R. and Sing, C. F. (1986). The use of measured genotype information in the analysis of quantitative phenotypes in man. I. Models and analytical methods. Annals of Human Genetics 50, 181-194.

Boes, J., Medley, G. F., Eriksen, L., Roepstorff, A. and Nansen, P. (1998). Distribution of Ascaris suum in experimentally and naturally infected pigs and comparison with Ascaris lumbricoides infections in humans. Parasitology 117, 589-596.

Brown, H. W. (1927). A study of the regularity of egg-production of Ascaris lumbricoides, Necator americanus and Trichuris trichiura. Fournal of Parasitology 14, 110-119.

Charlier, C., Coppieters, W., Rollin, F., Desmecht, D., Agerholm, J.S., Cambisano, N., Carta, E., Dardano, S., Dive, M., Fasquelle, C., Frennet, J. C., Hanset, R., Hubin, X., Jorgensen, C., Karim, L., Kent, M., Harvey, K., Pearce, B. R., Simon, P., Tama, N., Nie, H., Vandeputte, S., Lien, S., Longeri, M., Fredholm, M., Harvey, R. J. and Georges, M. (2008). Highly effective SNP-based association mapping and management of recessive defects in livestock. Nature Genetics 40, 449-454.

Copeman, D. B. and Gaafar, S. M. (1972). Sequential development of hepatic lesions of ascaridosis in colostrum-deprived pigs. Australian Veterinary Fournal 48, 263-268.

Coppieters, W., Mes, T.H., Druet, T., Farnir, F., Tamma, N., Schrooten, C., Cornelissen, A. W., Georges, M. and Ploeger, H. W. (2009). Mapping QTL influencing gastrointestinal nematode burden in Dutch Holstein-Friesian dairy cattle. BMC Genomics 10, 96.

Coustau, C., Chevillon, C. and ffrench-Constant, R. (2000). Resistance to xenobiotics and parasites: can we count the cost? Trends in Ecology and Evolution 15, 378-383.

Crofton, H. D. (1971). A model of host-parasite relationships. Parasitology 63, 343-364

Croll, N. A., Anderson, R. M., Gyorkos, T.W. and Ghadirian, E. (1982). The population biology and control of Ascaris lumbricoides in a rural community in Iran. Transactions of the Royal Society of Tropical Medicine and Hygiene 76, 187-197.

Davies, G., Stear, M. J., Benothman, M., Abuagob, O., Kerr, A., Mitchell, S. and Bishop, S. C. (2006). Quantitative trait loci associated with parasitic infection in Scottish Blackface sheep. Heredity 96, 252-258. Dawson, H.D., Beshah, E., Nishi, S., Solano-Aguilar, G., Morimoto, M., Zhao, A., Madden, K. B., Ledbetter, T. K., Dubey, J. P., Shea-Donohue, T., Lunney, J. K. and Urban, J. F., Jr. (2005). Localized multigene expression patterns support an evolving Th1/Th2-like paradigm in response to infections with Toxoplasma gondii and Ascaris suum. Infection and Immunity 73, 1116-1128.

Dermitzakis, E. T. and Clark, A. G. (2009). Life after GWA studies. Science 326, 239-240.

Dominik, S., Hunt, P.W., McNally, J., Murrell, A., Hall, A. and Purvis, I. W. (2010). Detection of quantitative trait loci for internal parasite resistance in sheep. I. Linkage analysis in a Romney $\times$ Merino sheep backcross population. Parasitology 137, 1275-1282.

Dow, C. and Jarrett, W. F. H. (1960). Age, strain and sex differences in susceptibility to Cysticercus fasciolaris in the mouse. Experimental Parasitology 10, 72-74. 
Eriksen, L., Andersen, S., Nielsen, K., Pedersen, A. and Nielsen, J. (1980). Experimental Ascaris suum infection in pigs. Serological response, eosinophilia in peripheral blood, occurrence of white spots in the liver and worm recovery from the intestine. Nordisk veterinarmedicin 32 , 233-242.

Eriksen, L., Lind, P., Nansen, P., Roepstorff, A. and Urban, J. (1992). Resistance to Ascaris suum in parasite naive and naturally exposed growers, finishers and sows. Veterinary Parasitology 41, 137-149.

Gasbarre, L. C., Leighton, E. A. and Davies, C. J. (1993). Influence of host genetics upon antibody responses against gastrointestinal nematode infections in cattle. Veterinary Parasitology 46, 81-91.

Gauly, M., Bauer, C., Preisinger, R. and Erhardt, G. (2002). Genetic differences of Ascaridia galli egg output in laying hens following a single dose infection. Veterinary Parasitology 103, 99-107.

Goddard, M. E. and Hayes, B. J. (2007). Genomic selection. Fournal of Animal Breeding and Genetics 124, 323-330.

Gray, G. D. (1995). Genetic variation in resistance to parasites. In Breeding for Resistance to Infectious Diseases in Small Ruminants (ed. Gray, G. D. Woolaston, R. R. and Eaton, B. T.), pp. 43-52. ACIAR Monograph No. 34 Australian Centre for International Agricultural Research, Canberra, Australia.

Groenen, M. A., Archibald, A. L., Uenishi, H., Tuggle, C. K., Takeuchi, Y., Rothschild, M.F., Rogel-Gaillard, C., Park, C. Milan, D., Megens, H. J., Li, S., Larkin, D. M., Kim, H., Frantz, L. A., Caccamo, M., Ahn, H., Aken, B. L., Anselmo, A., Anthon, C., Auvil, L., Badaoui, B., Beattie, C. W., Bendixen, C., Berman, D., Blecha, F., Blomberg, J., Bolund, L., Bosse, M., Botti, S. Bujie, Z. et al. (2012). Analyses of pig genomes provide insight into porcine demography and evolution. Nature 491, 393-398.

Hassan, M., Good, B., Hanrahan, J.P., Campion, D., Sayers, G., Mulcahy, G. and Sweeney, T. (2011). The dynamic influence of the DRB1*1101 allele on the resistance of sheep to experimental Teladorsagia circumcincta infection. Veterinary Research 42, 46.

Haugegaard, J. (2010). Prevalence of nematodes in Danish industrialized sow farms with loose housed sows in dynamic groups. Veterinary Parasitology 168, 156-159.

Havill, L. M., Dyer, T. D., Richardson, D. K., Mahaney, M. C. and Blangero, J. (2005). The quantitative trait linkage disequilibrium test: a more powerful alternative to the quantitative transmission disequilibrium test for use in the absence of population stratification. BMC Genetics 6 (Suppl. 1), S91.

Helwigh, A. B. and Nansen, P. (1999). Establishment of Ascaris suum in the pig: development of immunity following a single primary infection. Acta Veterinaria Scandinavica 40, 121-132.

Hoste, H. and Torres-Acosta, J. F. (2011). Non chemical control of helminths in ruminants: adapting solutions for changing worms in a changing world. Veterinary Parasitology 180, 144-154.

Iraqi, F. A., Behnke, J. M., Menge, D. M., Lowe, A. M., Teale, A. J., Gibson, J. P., Baker, L. R. and Wakelin, D. R. (2003). Chromosomal regions controlling resistance to gastro-intestinal nematode infections in mice. Mammalian Genome 14, 184-191.

Johnson, J. C., Jr., Stewart, T. B. and Hale, O. M. (1975). Differential responses of Duroc, Hampshire, and crossbred pigs to a superimposed experimental infection with the intestinal threadworm, Strongyloides ransomi. Fournal of Parasitology 61, 517-524.

Jorgensen, R. J., Nansen, P., Nielsen, K., Eriksen, L. and Andersen, S. (1975). Experimental Ascaris suum infection in pig. Population kinetics following low and high levels of primary infection in piglets. Veterinary Parasitology 1, 151-157.

Jungersen, G., Eriksen, L., Nansen, P. and Fagerholm, H.P. (1997). Sex-manipulated Ascaris suum infections in pigs: implications for reproduction. Parasitology 115, 439-442.

Jungersen, G., Eriksen, L., Roepstorff, A., Lind, P., Meeusen, E. N., Rasmussen, T. and Nansen, P. (1999). Experimental Ascaris suum infection in the pig: protective memory response after three immunizations and effect of intestinal adult worm population. Parasite Immunology 21, 619-630.

Kemper, K.E., Emery, D. L., Bishop, S. C., Oddy, H., Hayes, B. J., Dominik, S., Henshall, J.M. and Goddard, M.E. (2011). The distribution of SNP marker effects for faecal worm egg count in sheep, and the feasibility of using these markers to predict genetic merit for resistance to worm infections. Genetics Research 93, 203-219.

Kloosterman, A., Parmentier, H. K. and Ploeger, H. W. (1992). Breeding cattle and sheep for resistance to gastrointestinal nematodes. Parasitology Today 8, 330-335.

Lewis, R., Behnke, J. M., Stafford, P. and Holland, C. V. (2006). The development of a mouse model to explore resistance and susceptibility to early Ascaris suum infection. Parasitology 132, 289-300.
Manolio, T.A., Collins, F.S., Cox, N. J., Goldstein, D. B., Hindorff, L. A., Hunter, D. J., McCarthy, M. I., Ramos, E. M., Cardon, L. R., Chakravarti, A., Cho, J.H., Guttmacher, A. E. Kong, A., Kruglyak, L., Mardis, E., Rotimi, C. N., Slatkin, M., Valle, D., Whittemore, A.S., Boehnke, M., Clark, A. G., Eichler, E. E., Gibson, G., Haines, J. L., Mackay, T.F., McCarroll, S. A. and Visscher, P.M. (2009). Finding the missing heritability of complex diseases. Nature 461, 747-753.

Masure, D., Vlaminck, J., Wang, T., Chiers, K., Van den Broeck, W., Vercruysse, J. and Geldhof, P. (2013). A role for eosinophils in the intestinal immunity against infective Ascaris suum larvae. PLoS Neglected Tropical Diseases 7, e2138

Mejer, H. and Roepstorff, A. (2006). Ascaris suum infections in pigs born and raised on contaminated paddocks. Parasitology 133, 305-312.

Miller, S. A., Dykes, D. D. and Polesky, H. F. (1988). A simple salting out procedure for extracting DNA from human nucleated cells. Nucleic Acids Research 16, 1215.

Miquel, N., Roepstorff, A., Bailey, M. and Eriksen, L. (2005). Host immune reactions and worm kinetics during the expulsion of Ascaris suum in pigs. Parasite Immunology 27, 79-88.

Mitchell, G. F., Hogarth-Scott, R. S., Edwards, R. D., Lewers, H. M. Cousins, G. and Moore, T. (1976). Studies on immune responses to parasite antigens in mice. I. Ascaris suum larvae numbers and antiphosphorylcholine responses in infected mice of various strains and in hypothymic nu/nu mice. International Archives of Allergy and Applied Immunology 52, 64-78.

Mugambi, J. M., Bain, R. K., Wanyangu, S. W., Ihiga, M. A. Duncan, J. L., Murray, M. and Stear, M. J. (1997). Resistance of four sheep breeds to natural and subsequent artificial Haemonchus contortus infection. Veterinary Parasitology 69, 265-273.

Nejsum, P., Roepstorff, A., Jorgensen, C. B., Fredholm, M. Goring, H. H., Anderson, T.J. and Thamsborg, S. M. (2009a). High heritability for Ascaris and Trichuris infection levels in pigs. Heredity 102, 357-364

Nejsum, P., Thamsborg, S. M., Petersen, H. H., Kringel, H., Fredholm, M. and Roepstorff, A. (2009b). Population dynamics of Ascaris suum in trickle-infected pigs. Fournal of Parasitology 95, 10481053

Nielsen, B., Jorgensen, C. B., Vernersen, A. and Fredholm, M. (2009). Effect of selection for E. coli $\mathrm{F} 4 \mathrm{ab} / \mathrm{ac}$ resistance in pigs. 60th Annual Meeting of the European Association for Animal Production, Barcelona, 2008

Nissen, S., Poulsen, I. H., Nejsum, P., Olsen, A., Roepstorff, A., Rubaire-Akiiki, C. and Thamsborg, S. M. (2011). Prevalence of gastrointestinal nematodes in growing pigs in Kabale District in Uganda Tropical Animal Health and Production 43, 567-572.

Oksanen, A., Eriksen, L., Roepstorff, A., Ilsoe, B., Nansen, P. and Lind, P. (1990). Embryonation and infectivity of Ascaris suum eggs. A comparison of eggs collected from worm uteri with eggs isolated from pig faeces. Acta Veterinaria Scandinavica 31, 393-398.

Oliveira, M. C., Alencar, M. M., Chagas, A.C., Giglioti, R. and Oliveira, H. N. (2009). Gastrointestinal nematode infection in beef cattle of different genetic groups in Brazil. Veterinary Parasitology 166 249-254.

O'Lorcain, P. and Holland, C. V. (2000). The public health importance of Ascaris lumbricoides. Parasitology 121, S51-S71.

Peng, W., Zhou, X., Cui, X., Crompton, D. W., Whitehead, R. R., Xiong, J., Wu, H., Peng, J., Yang, Y., Wu, X., Xu, K. and Yan, Y. (1996) Ascaris, people and pigs in a rural community of Jiangxi Province, China. Parasitology 113, 545-557.

Pérez, J., García, P. M., Mozos, E., Bautista, M. J. and Carrasco, L. (2001). Immunohistochemical characterization of hepatic lesions associated with migrating larvae of Ascaris suum in pigs. Fournal of Comparative Pathology 124, 200-206.

Petkevicius, S., Bjorn, H., Roepstorff, A., Nansen, P., Bach Knudsen, K. E., Barnes, E. H. and Jensen, K. (1995). The effect of two types of diet on populations of Ascaris suum and Oesophagostomum dentatum in experimentally infected pigs. Parasitology 111, 395-401.

Pulendran, B. and Artis, D. (2012). New paradigms in type 2 immunity Science 337, 431-435.

Quinnell, R. J. (2003). Genetics of susceptibility to human helminth infection. International Fournal for Parasitology 33, 1219-1231.

R Core Team (2012). R: A Language and Environment for Statistical Computing. R Foundation for Statistical Computing, Vienna, Austria. Riggio, V., Matika, O., Pong-Wong, R., Stear, M. J. and Bishop, S. C. (2013). Genome-wide association and regional heritability mapping to identify loci underlying variation in nematode resistance and body weight in Scottish Blackface lambs. Heredity 110, 420-429. 
Roepstorff, A. (1998). Natural Ascaris suum infections in swine diagnosed by coprological and serological (ELISA) methods. Parasitology Research $\mathbf{8 4}$, 537-543.

Roepstorff, A. and Murrell, K.D. (1997). Transmission dynamics of helminth parasites of pigs on continuous pasture: Ascaris suum and Trichuris suis. International Fournal for Parasitology 27, 563-572.

Roepstorff, A. and Nansen, P. (1998). Epidemiology, Diagnosis and Control of Helminth Parasites of Swine. Food and Agriculture Organization (FAO), Rome.

Roepstorff, A., Eriksen, L., Slotved, H. C. and Nansen, P. (1997). Experimental Ascaris suum infection in the pig: worm population kinetics following single inoculations with three doses of infective eggs. Parasitology 115, 443-452.

Ronéus, O. (1966). Studies on the aetiology and pathogenesis of white spots in the liver of pigs. Acta Veterinaria Scandinavica 7 (Suppl. 16), 1-112.

Saddiqi, H. A., Jabbar, A., Sarwar, M., Iqbal, Z., Muhammad, G., Nisa, M. and Shahzad, A. (2011). Small ruminant resistance against gastrointestinal nematodes: a case of Haemonchus contortus. Parasitology Research 109, 1483-1500.

Sallé, G., Jacquiet, P., Gruner, L., Cortet, J., Sauvé, C., Prévot, F., Grisez, C., Bergeaud, J. P., Schibler, L., Tircazes, A., Francois, D., Pery, C., Bouvier, F., Thouly, J. C., Brunel, J. C., Legarra, A., Elsen, J. M., Bouix, J., Rupp, R. and Moreno, C. R. (2012). A genome scan for QTL affecting resistance to Haemonchus contortus in sheep. Fournal of Animal Science 90, 4690-4705.

Schwartz, B. (1959). Experimental infection of pigs with Ascaris suum. American Fournal of Veterinary Research 20, 7-13.

Scott, J. A. and Headlee, W. H. (1938). Studies in Egypt on the correction of helminth egg count data for the size and consistency of stools. American Fournal of Hygiene 27, 176-195.

Silva, M. V., Sonstegard, T.S., Hanotte, O., Mugambi, J. M., Garcia, J. F., Nagda, S., Gibson, J. P., Iraqi, F. A., McClintock, A. E., Kemp, S. J., Boettcher, P. J., Malek, M., Van Tassell, C. P. and Baker, R. L. (2012). Identification of quantitative trait loci affecting resistance to gastrointestinal parasites in a double backcross population of Red Maasai and Dorper sheep. Animal Genetics 43, 63-71.

Skallerup, P., Nejsum, P., Jorgensen, C. B., Goring, H. H., KarlskovMortensen, P., Archibald, A. L., Fredholm, M. and Thamsborg, S. M. (2012). Detection of a quantitative trait locus associated with resistance to Ascaris suum infection in pigs. International Fournal for Parasitology 42, 383-391

Slotved, H. C., Barnes, E. H., Eriksen, L., Roepstorff, A., Nansen, P. and Bjorn, H. (1997). Use of an agar-gel technique for large scale application to recover Ascaris suum larvae from intestinal contents of pigs. Acta Veterinaria Scandinavica 38, 207-212.

Stankiewicz, M. and Jeska, E. L. (1990). Evaluation of pyrantel-tartrate abbreviated Ascaris suum infections for the development of resistance in young pigs against migrating larvae. International fournal for Parasitology $20,77-81$

Stear, M.J., Bairden, K., Duncan, J.L., Holmes, P.H., McKellar, Q. A., Park, M., Strain, S., Murray, M., Bishop, S. C. and Gettinby, G. (1997). How hosts control worms. Nature 389, 27.

Stear, M. J., Strain, S. and Bishop, S. C. (1999). How lambs control infection with Ostertagia circumcincta. Veterinary Immunology and Immunopathology 72, 213-218.

Thamsborg, S. M., Nejsum, P. and Mejer, H. (2013). Impact of Ascaris suum in livestock. In Ascaris: The Neglected Parasite (ed. Holland, C. V.), pp. 363-381. Elsevier, London, UK.

Urban, J. F., Jr., Alizadeh, H. and Romanowski, R. D. (1988). Ascaris suum: development of intestinal immunity to infective second-stage larvae in swine. Experimental Parasitology 66, 66-77.

Vlaminck, J., Nejsum, P., Vangroenweghe, F., Thamsborg, S. M., Vercruysse, J. and Geldhof, P. (2012). Evaluation of a serodiagnostic test using Ascaris suum haemoglobin for the detection of roundworm infections in pig populations. Veterinary Parasitology 189 267-273.

Williams-Blangero, S., Subedi, J., Upadhayay, R. P., Manral, D. B., Rai, D. R., Jha, B., Robinson, E.S. and Blangero, J. (1999). Genetic analysis of susceptibility to infection with Ascaris lumbricoides. American Fournal of Tropical Medicine and Hygiene 60, 921-926.

Wolc, A., Arango, J., Settar, P., Fulton, J. E., O’Sullivan, N.P., Preisinger, R., Habier, D., Fernando, R., Garrick, D. J., Hill, W. G. and Dekkers, J. C. (2012). Genome-wide association analysis and genetic architecture of egg weight and egg uniformity in layer chickens. Animal Genetics 43 (Suppl. 1), 87-96.

Yoshida, A., Nagayasu, E., Horii, Y. and Maruyama, H. (2012). A novel C-type lectin identified by EST analysis in tissue migratory larvae of Ascaris suum. Parasitology Research 110, 1583-1586.

Zaros, L. G., Bricarello, P. A., Amarante, A. F., Rocha, R.A., Kooyman, F. N., De Vries, E. and Coutinho, L. L. (2010). Cytokine gene expression in response to Haemonchus placei infections in Nelore cattle. Veterinary Parasitology 171, 68-73.

Zinsstag, J., Ankers, P., Njie, M., Smith, T., Pandey, V. S., Pfister, K. and Tanner, M. (2000). Heritability of gastrointestinal nematode faecal egg counts in West African village N'Dama cattle and its relation to age. Veterinary Parasitology 89, 71-78. 